Empirical study

\title{
Adolescents' autonomous functioning and implicit theories of ability as predictors of their school achievement and week-to-week study regulation and well-being
}

\author{
Athanasios Mouratidis ${ }^{\mathrm{a}, *}$, Aikaterini Michou $^{\mathrm{b}}$, Aikaterini Vassiou $^{\mathrm{c}}$ \\ ${ }^{a}$ Department of Psychology, Hacettepe University, Beytepe Campus 06800, Ankara, Turkey \\ ${ }^{\mathrm{b}}$ Graduate School of Education, Bilkent University, 06800 Bilkent, Ankara, Turkey \\ ${ }^{\mathrm{c}}$ Department of Primary Education, University of Thessaly, Volos, Greece
}

\section{A R T I C L E I N F O}

\section{Article history:}

Available online 14 September 2016

\section{Keywords:}

Motivation

Implicit theories

Self-determination

Academic achievement

Students

Diary study

\begin{abstract}
A B S T R A C T
Research on students' motivation has mainly focused on interpersonal differences rather than on the ongoing, intrapersonal dynamics that forge students' everyday life. In this five-month longitudinal (diary) study, we recruited a sample of 179 high school students from Greece (35.8\% males; $M_{\text {age }}=16.27$; $S D=1.02$ ) to investigate through multilevel analyses the ongoing dynamics of students' motivation. We did so by examining the relation between autonomous functioning and aspects of study regulation (namely, study efforts and procrastination) and well-being (namely, subjective vitality and depressive feelings). After controlling for perceived competence, we found week-to-week autonomous functioning to relate positively to study efforts and subjective vitality and negatively to procrastination and depressive feelings. Interestingly, implicit theories of ability - the degree to which one believes that ability is fixed or amenable - were found to moderate the week-to-week relations of autonomous functioning to study efforts and homework procrastination. In particular, autonomous functioning co-varied positively to study efforts and negatively to homework procrastination only among students who believed that ability is malleable. Also, beliefs that ability is fixed predicted poorer grades, lower mean levels of study efforts, and higher homework procrastination. The results underscore the necessity of taking a more dynamic view when studying motivational phenomena and the importance of jointly considering the implicit theory framework and self-determination theory.
\end{abstract}

(c) 2016 Elsevier Inc. All rights reserved.

\section{Introduction}

Students experience several ups and downs within a school year. At times they may be fully committed to do their homework and experience higher well-being while at other times they may tend to procrastinate their homework and feel despondent. The issue of week-to-week fluctuation of students' study regulation and well-being has received far less attention compared to the research question of why some students, on average, better regulate their study behavior and affect than others. This is an important oversight because investigating the intrapersonal fluctuations of students' motivational processes and outcomes in conjunction with the interpersonal differences can help us better comprehend the ongoing dynamics that students experience in their everyday lives.

\footnotetext{
* Corresponding author.

E-mail addresses: athanasios@hacettepe.edu.tr (A. Mouratidis), aliki.michou@ bilkent.edu.tr (A. Michou), ekvasiou@uth.gr (A. Vassiou).
}

Other things being equal, we propose that students' intrapersonal fluctuation of study regulation and well-being corresponds to a respective fluctuation of autonomous functioning (as reflected by students' awareness of self, which we consider an important element of people's disposition for autonomous functioning - see Weinstein, Przybylski, \& Ryan, 2013). Specifically, we aimed to investigate to what extent the week-to-week fluctuation of students' autonomous functioning co-varies with two markers of study regulation (i.e., study efforts and homework procrastination) and two markers of well-being (i.e., subjective vitality and depressive feelings).

Further, we examined whether this co-variation differs among students who differ in implicit theories they hold about ability. Implicit theories refer to the beliefs that students hold about the nature of the ability; that is, whether ability is a fixed trait or can be developed through effort and practice (Dweck, 1999). By focusing on implicit theories, we aimed to test whether such ability beliefs moderate the week-to-week associations of autonomous functioning to study regulation and perhaps to well-being. In doing 
so, we attempted to put two of the most influential motivational theories in educational contexts, Self-Determination Theory (SDT; Deci \& Ryan, 2000) and implicit theories of ability (Dweck, 1999) next to each other to shed some light on the dynamics of students' week-to-week school-related functioning. Also, after controlling for academic perceived competence, we investigated whether ability beliefs predict grades five months later.

\subsection{Autonomous functioning}

According to SDT (Deci \& Ryan, 2000), students may study because they feel coerced to do so due to some internal or external pressures or because they truly want it. When they perceive studying as a should-be task, they are presumed to be under some internal or external pressure, and thus to be controlled motivated. In contrast, when they consider studying as an enjoyable or valuable activity, they are said to function in an autonomous way; that is, to be more authentic, and thus to have better access to their motives, emotions, and the true meanings underpinning their actions (Weinstein et al., 2013). In our research we focused on awareness of self - the self-knowledge that is accessible and available upon request by one's self - as one of the key elements that characterizes the reflective and thoughtful endorsement of one's action and eventually one's autonomous functioning (Ryan, Huta, \& Deci, 2008).

Numerous studies focusing on interpersonal differences in educational contexts have shown that autonomous functioning, as compared to controlled functioning, is linked with more desired outcomes such as better concentration (Vansteenkiste, Zhou, Lens, \& Soenens, 2005) higher well-being (Guay, Ratelle, \& Chanal, 2008) and less homework procrastination (Katz, Eilot, \& Nevo, 2014; Senecal, Julien, \& Guay, 2003). Most likely, this is because one of the core concepts of autonomous functioning awareness of self - has been related to higher inhibitory-control which is necessary for executive functioning in school-related tasks (Oberle, Schonert-Reichl, Lawlor, \& Thomson, 2012). Furthermore, a few diary studies which have been conducted so far have shown that daily autonomous functioning, as reflected through autonomous motivation (Bartholomew, Ntoumanis, Ryan, Bosch, \& Thogersen-Ntoumani, 2011; Gagné, Ryan, \& Bargmann, 2003) or through daily need satisfaction (Bartholomew et al., 2011), relates positively to well-being in adolescents (Gagné et al., 2003) or young adults (Moller, Deci, \& Elliot, 2010; Reis, Sheldon, Gable, Roscoe, \& Ryan, 2000; Sheldon \& Niemiec, 2006; Sheldon, Ryan, \& Reis, 1996).

Taken together, the literature suggests that autonomous functioning predicts both interpersonal differences and intrapersonal fluctuations of desired correlates. However, the degree of confluence between autonomous functioning and positive correlates at the intrapersonal level has been mainly investigated with respect to affective correlates. There is much to be known with respect to behaviors that are partly determined by the affordances and the constraints that are set by the school context. In particular, while it makes sense, according to SDT (Deci \& Ryan, 2000), to expect autonomous functioning to co-vary with well-being at the intrapersonal level, we cannot tell for sure that a similar covariation also includes ostensibly should-be behaviors, such as homework study, that a student may have only partly, if at all, internalized. Drawing from SDT, we expect that this may be true for study-related behaviors, but to the best of our knowledge no empirical data have shown such a link yet. Providing evidence that regardless of its intrapersonal fluctuation across time, autonomous functioning does relate not only to well-being but also to study regulation at the intrapersonal level in a consistent manner will underscore the beneficial role of autonomous functioning on tasks, such as doing homework, which are not always perceived as inherently enjoying (Deci, Eghrari, Patrick, \& Leone, 1994).

Furthermore, it remains unclear whether the degree of confluence between autonomous functioning and study regulation differs among students, depending on the beliefs they may hold about the importance of effort. To investigate this possibility, we relied on Dweck's conceptualization of students' implicit beliefs about the nature of ability - to what extent they believe that ability can be developed, presumably through effort, or remains relatively stable across time (Dweck, 1999). We opted for ability beliefs because they are considered to predict effort in school-work (Bodill \& Roberts, 2013; Hong, Chiu, Dweck, Lin, \& Wan, 1999).

\subsection{Implicit ability beliefs}

In their influential work, Carole Dweck and associates have shown that the lay theories that people hold about whether human attributes are fixed or malleable result in different psychological processes and outcomes (Dweck \& Leggett, 1988; Molden \& Dweck, 2006). Dating back to '80s Dweck (1986) has started investigating why students of the same ability may exhibit totally different motivational patterns after failure. She reasoned, and showed, that students who believed that ability is a fixed trait, displayed a maladaptive response pattern after failure compared to students who believed that ability can be developed through effort and mastery striving. Although Dweck found no differences in persistence and challenge-seeking between students holding either entity or incremental beliefs after success, she revealed that compared to students with incremental beliefs, their counterparts with entity beliefs exhibited less resilience after failure as they were less likely to persist and seek any further challenges (Cain \& Dweck, 1995; Dweck \& Leggett, 1988).

An ever growing body of research has indicated that students holding incremental beliefs, as compared to those holding entity beliefs, show a more adaptive response pattern in a wide array of outcomes that extend from the academic domain to the social one (Burnette, O’Boyle, VanEpps, Pollack, \& Finkel, 2013; Yeager \& Dweck, 2012; Yeager, Trzesniewski, \& Dweck, 2013; Yeager et al., 2014). Relevant to the focus of our study, past research has indicated that students who favored incremental over entity beliefs have higher grades (Romero, Master, Paunesku, Dweck, \& Gross, 2014), endorse more learning goals (Blackwell, Trzesniewski, \& Dweck, 2007), use better reading strategies (Braasch, Braten, Stromso, \& Anmarkrud, 2014), and practice more (Cury, Da Fonseca, Zahn, \& Elliot, 2008). Conversely, entity beliefs have been linked with decreases in intrinsic motivation (Haimovitz, Wormington, \& Corpus, 2011) and academic disengagement (Martin, Nejad, Colmar, \& Liem, 2013).

Taken together, these findings suggest that students who hold incremental beliefs are more likely to succeed academically, most likely because they use more effective studying strategies - for instance, by putting more effort in homework tasks and by procrastinating less. Indeed, study efforts have been found to relate positively to incremental beliefs (Jones, Wilkins, Long, \& Wang, 2012) and negatively to entity beliefs (Bodill \& Roberts, 2013) whereas procrastination has been associated positively with entity beliefs (Howell \& Buro, 2009).

An issue, which has only partly addressed relates to whether ability beliefs, can predict students' study efforts and procrastination, irrespectively of how much these fluctuate from week to week. Showing such a relation would provide further evidence of the potential pervasive role of such cognitions on students' study-related functioning. Ability beliefs might also predict students' week-to-week fluctuation of subjective vitality and depressive feelings. However, such a relation seems less likely because these affective correlates seem conceptually more distant from 
ability beliefs than the school-related correlates of study efforts and procrastination which are more relevant to school-related ability beliefs.

As said, an issue that has remained underexplored concerns the likely moderating role that ability beliefs may play on week-toweek associations between autonomous functioning and study regulation, and perhaps on well-being. For instance, do students who favor entity beliefs as compared to those favoring incremental beliefs exert less effort on studying, and procrastinate more even in days in which they feel they function autonomously? Or, do they benefit more in such days? In our study we aimed to address this issue as well.

\subsection{This study}

In this 5-month longitudinal research we followed up a sample of high-school students and investigated, at the intrapersonal level, the degree to which students' week-to-week autonomous functioning co-varies with study efforts and homework procrastination as well as with subjective vitality and depressive feelings. Furthermore, while controlling for perceived competence we explored whether the observed week-to-week associations of autonomous functioning to study regulation and well-being would differ as a function of students' high versus low entity beliefs about ability. Finally, we examined whether entity beliefs predict betweenstudent differences in study efforts and homework procrastination as well as grades after controlling for academic perceived competence. Perceived competence was included because it is considered as a key factor across many motivational theories (Wigfield \& Eccles, 2000), including SDT (Deci \& Ryan, 2000) that considers competence need satisfaction (as reflected through perceived competence) to facilitate autonomous functioning and in turn positive outcomes. Several studies have found perceived competence to relate positively to autonomous functioning (e.g., Vallerand, Fortier, \& Guay, 1997), study efforts (e.g., Shell \& Husman, 2008), and academic achievement (e.g., Grolnick, Ryan, \& Deci, 1991; Vallerand et al., 1997). Therefore, we considered important to control for perceived competence before examining the relations of autonomous functioning to study efforts and procrastination. Likewise, research has shown that although entity beliefs (or incremental beliefs) do not associate with perceived competence, they do predict subsequent grades, much like perceived competence does (Cury, Elliot, Da Fonseca, \& Moller, 2006). So, taking into account perceived competence was again deemed necessary.

We formulated the following three hypotheses. First, we relied on SDT (Deci \& Ryan, 2000) and prior empirical evidence (e.g., Bartholomew et al., 2011; Patrick, Knee, Canevello, \& Lonsbary, 2007; Reis et al., 2000) and expected the week-to-week autonomous functioning to relate positively to the respective week-toweek study efforts and subjective vitality and negatively to the respective week-to-week, homework procrastination and depressive feelings (Hypothesis 1). Our hypothesis was based on the assumption that a student who has better access to his or her motives and emotions is more likely to experience higher wellbeing (Weinstein et al., 2013) and exert inhibitory control when needed (Oberle et al., 2012) and thus put more effort into studying and procrastinate less.

Second, we examined whether ability beliefs would moderate week-to-week relations of autonomous functioning to study regulation (i.e., study efforts and procrastination) after controlling for interpersonal differences in perceived competence. Extrapolating from the sensitization hypothesis (Moller et al., 2010), which claims people who in general satisfy their basic psychological needs in their lives benefit even more during days that they satisfy their needs (because they are more "sensitive" on cues that trigger needs satisfaction on a daily basis), we explored whether students with adaptive motivational beliefs (i.e., those who disfavor entity beliefs) would report even more study effort and less homework procrastination during the days they would feel more autonomous functioning. We expected no such moderation for subjective vitality or depressive feelings as prior research has indicated that such moderation is more likely to take place among constructs that conceptually match (Reis et al., 2000). In that vein for instance, Reis et al. (2000) indicated that person-level self-determination, effectance, and connectedness moderated the day-to-day relations between well-being and, respectively, autonomy, competence, and relatedness need satisfaction (see also Moller et al., 2010). Therefore, although we anticipated ability beliefs about one's school competence to moderate the relation between week-toweek autonomous functioning and study-related correlates (as the latter are conceptually closer to school-related ability beliefs), we hypothesized that this would not be the case for the relation between week-to-week autonomous functioning and indices of well-being (i.e., subjective vitality and depressive symptoms) given their conceptual space with entity beliefs - we presumed that wellbeing lies, compared to study-related correlates, more at the periphery of the nomological network of school-related ability beliefs (Cronbach \& Meehl, 1955) (Hypothesis 2).

Third, moving from the intrapersonal level to the interpersonal one, we anticipated that even after controlling for perceived competence, entity beliefs would predict less study efforts and more procrastination but not subjective vitality or depressive feelings as these indices are less likely to be explained by a cognitive-based predictor (Hypothesis 3). We expected ability beliefs to predict the study-related correlates, because the more students believe that ability is a fixed entity, the less likely they are to see a reason to invest more effort in studying (Jones et al., 2012) as for these students the locus of control seems to reside to some uncontrollable sources (Bodill \& Roberts, 2013). Concomitantly, students with strong entity beliefs may tend to procrastinate their homework more as postponing a should-be-done activity for a later time and substitute it with an enjoying one, may help them cope with the negative emotions arising due to school-related tasks (King, McInerney, \& Watkins, 2012) and with an uncomfortable situation where any effort for studying hard is futile (Cury et al., 2008).

To address all the above hypotheses, we employed a five-month longitudinal (diary) study. We recruited a sample of high school students where at the outset (main day of data collection) participants reported their ability beliefs and perceptions of academicrelated competence, and a month later, reported for six consecutive weeks (diary phase) their week-to-week autonomous functioning, study efforts, and homework procrastination as well as subjective vitality and depressive feelings. Students' final grades were recorded at the end of the school year.

\section{Method}

\subsection{Participants and procedures}

The original sample was consisted of 187 students from a public high school located in a small city in Northern Greece. Eight students were dropped; seven of them because they were absent in the day of the main data collection and the eighth one because she has not filled daily questionnaire during the diary phase. Therefore, the retained sample was $N=179$ (35.8\% males; five students omitted reporting their gender). Students $\left(M_{\text {age }}=16.27\right.$; $S D=1.02$ ) belonged to three 10th-grade ( $N=66 ; 38.5 \%$ males), two 11 th-grade $(N=41 ; 50.0 \%$ males $)$, and three 12th-grade $(N=72 ; 28.2 \%$ males) classes.

The study was conducted in the framework of an obligatory course with the name "Research Project". In this course the teacher 
chooses the research project they will carry out throughout a school semester in collaboration with the students. The chosen subject of the research project the school year of the study was "Students' Motivation and Affect". The project was aiming at facilitating students to reflect on people's motivation and feelings in various social situations A research assistant, who was serving as a teacher at that particular school and who was blind to the research hypotheses, explained students the purpose of this part of the research project, its timeline, and the procedures that were to be followed in each class group separately. She assured that participation in the completion of the questionnaires was voluntary and that all information would remain confidential. Therefore, while the participation in the course was obligatory as it was part of the school curriculum, participation in the completion of the questionnaires was not. No student denied participation.

The study was divided into three phases. In the beginning of the second semester (January), students filled in a battery of questionnaires aiming to assess their school-related ability beliefs (i.e., implicit theories of ability about whether school-related learning ability is fixed or malleable) and perceived competence during the first twenty minutes of a 45 -min class session. The second phase began a month later and lasted six weeks (February to March). Students filled in a one-page diary-like questionnaire on a weekly basis. In that short questionnaire they reported the degree to which they felt that they were autonomously functioning (as reflected through awareness of self) during the preceding two to three days; they also reported to what extent they had been successfully regulating their study-related efforts and the degree to which they procrastinated their homework; likewise, they reported the degree to which they felt energetic and to what extent they experienced any depressive feelings. Finally, in the end of the second semester (and school year) students' final grades (grade point average of all the taught lessons) were recorded (and this was the third phase).

\subsection{Measures}

\subsubsection{Implicit theories of ability}

We adjusted three items referring to implicit theories of intelligence that Dweck and associates have introduced (Dweck, Chiu, \& Hong, 1995) to assess students' beliefs about whether school-related ability is fixed (entity beliefs) or can be cultivated (incremental beliefs). Students' indicated their (dis)agreement on a six-point Likert-type scale ( $1=$ Strongly disagree; $6=$ Strongly agree) in the following three items: "You have a certain amount of learning ability at school and you can't really do much to change it"; "Your learning ability at school is something about you that you can't change very much"; "At school you can learn new things, but you can't really change your basic intelligence". A pilot testing of the scale yielded acceptable internal consistency and the same was true in our main study (Cronbach alpha, $\alpha=0.85$ ). An average score was computed by the three items with higher scores reflecting stronger entity beliefs.

\subsubsection{Perceived competence}

We used four items from the Intrinsic Motivation Inventory (Ryan, Mims, \& Koestner, 1983) to assess the degree to which the students felt competent with respect to the school-related activities. The IMI has been developed throughout the last three decades and has been validated by McAuley, Duncan, and Tammen (1989). An example item reads, "I think I am pretty good at school-related activities" and the internal consistency was $\alpha=0.90$.

\subsubsection{Week-to-week autonomous functioning}

The five-item "Awareness of Oneself" subscale, which is part of the self-determination scale (Sheldon \& Deci, 1996), was employed to assess aspects of students' week-to-week autonomous functioning. The scale has been used in prior dairy studies (Reis et al., 2000; Sheldon et al., 1996). For the sake of brevity, the original format was somewhat changed so that the items were presented on a 5point Likert type format anchored in two bipolar statements. For example, the stem of an item read, "The last couple of days I felt my emotions were ..." was followed by two bipolar statements of "... alien to me" (1) and ... "belonged to me" (5). Higher scores reflected higher awareness of self and thus higher autonomous functioning. Computation of the reliability with a multilevel approach for which a between-person internal consistency, $\alpha$, was computed after taking into account the intrapersonal (i.e., repeated-measures) variance (Geldhof, Preacher, \& Zyphur, 2014) indicated an acceptable internal consistency $(\alpha=0.98)$.

\subsubsection{Week-to-week study efforts}

The relevant scale of the Motivated Strategies for Learning Questionnaire (Pintrich, Smith, Garcia, \& McKeachie, 1991) was adapted to assess the degree to which students effectively regulate their study homework-related efforts the last few days before each of the six assessment days (4 items; e.g., "The last couple of days, I work hard to study my lessons even if I didn't like what I was doing"). The between-person internal consistency was computed through the method suggested by Geldhof et al. (2014) was $\alpha=0.88$.

\subsubsection{Week-to-week procrastination}

Four items from the Questionnaire Concerning Study Management Abilities, which were originally developed in Dutch by Depreeuw (1998) and which are based on Lay's (1986) questionnaire, were translated and pilot tested. As in the pilot study, we used only four items to keep the diary questionnaire short and to reduce a likely burden on the students. The scale assesses students' tendency to postpone their studying schedule and replace it with non-studying activities. An example item reads, "The last couple of days I started studying later than I had intended to" and the between-person internal consistency of the scale (Geldhof et al., 2014) was $\alpha=0.91$.

\subsubsection{Week-to-week subjective vitality}

We used five items from the Subjective Vitality Scale (Ryan \& Frederick, 1997) to assess the degree to which students felt vigor and vital (sample item: "The last couple of days I felt energized"). The between-person reliability was $\alpha=0.98$.

\subsubsection{Week-to-week depressive feelings}

To assess to what extent students experienced depressive feelings, we asked them to respond to five items (e.g., "The last couple of days I felt lonely") that we had taken from the Center for Epidemiological Studies - Depression questionnaire (Radloff, 1977). The scale showed an acceptable between-person reliability $(\alpha=0.88)$.

\subsubsection{Grade point average}

In the end of the second semester (and school year) we recorded students' grade point average (GPA) of all the taught lessons, six of which were examined at the national level as a prerequisite for university entrance exams. The grading system in Greek secondary school system ranges from 1 to 20 , with the pass threshold lying at $9.6 \quad(1.0-9.5=$ fail; $\quad 9.6-12.5=$ fair; $\quad 12.6-15.0=$ good; $15.1-$ 18.5 = very good; $18.6-20=$ excellent $)$. 


\section{Results}

\subsection{Preliminary analyses}

Descriptive statistics and bivariate correlations at both the intrapersonal and interpersonal level are presented in Table 1. As can be noticed perceived competence and entity beliefs were uncorrelated. Also, perceived competence was related positively to GPA and the aggregated scores of autonomous functioning, effort regulation, and subjective vitality and negatively to the aggregated scores of procrastination and depressive feelings. In contrast, entity beliefs related negatively to aggregated scores of effort regulation and grades, and positively to aggregated score of procrastination. Although a MANOVA showed no significant gender differences (Wilk's $\Lambda=0.937, F[6,165]=1.81, p=0.09$ ), preliminary analyses showed that gender moderated some of the tested paths. Therefore, gender was included as a covariate.

\subsection{Main analyses}

\subsubsection{Plan of analyses}

Two pairs of multilevel models were set up, one for the studyrelated correlates (i.e., study efforts and procrastination) and another one for the affective correlates (i.e., subjective vitality and depressive feelings), to test (a) Hypothesis 1 (i.e., whether week-to-week autonomous functioning relates positively to study efforts and subjective vitality and negatively to homework procrastination and depressive feelings), (b) Hypothesis 2 (i.e., whether entity beliefs moderate these associations), and (c) Hypothesis 3 (i.e., whether entity beliefs would predict higher mean levels of study efforts and lower mean levels of homework procrastination). In all the four multilevel models the intrapersonal level was used to assess the degree of week-to-week relations of autonomous functioning to the two study-related (i.e., study efforts and procrastination) and two affective correlates (i.e., subjective vitality and depressive feelings) (Hypothesis 1 ). The entity beliefs and perceived competence were used as between-student moderators of the above associations (Hypothesis 2) and as predictors of students' mean level differences in study efforts, homework procrastination, subjective vitality, and depressive feelings (Hypothesis 3 ). Gender and perceived competence were also included as covariates at the between-student level.

Following the recommendations provided by (Enders \& Tofighi, 2007), we group-mean centered the intrapersonal predictor (i.e., autonomous functioning). At the between-student level, gender was uncentered $(-0.5=$ males; $0.5=$ females $)$. Through this coding scheme the intercept represented the whole sample and the gender coefficient reflected the differences between male and female students. Perceived competence and entity beliefs were grand-mean centered. The slopes of autonomous functioning (i.e., the relations of autonomous functioning to the four dependent variables) were allowed to vary from person to person randomly.

\subsubsection{Multilevel analyses}

The results from the multilevel models are shown in Table 2. At the intrapersonal level, and in partial support to Hypothesis 1, autonomous functioning co-varied positively with study efforts $\left(\beta_{10}=0.09\right)$ and subjective vitality $\left(\beta_{10}=0.25\right)$ and negatively with depressive feelings $\left(\beta_{10}=-0.24\right)$, although it was unrelated to procrastination $\left(\beta_{10}=-0.01\right)$. This finding suggests that, on average, the more students experienced autonomous functioning, the more effort they put on studying, the more energized they felt, and the less depressive feelings they experienced. Inspection of the variance components of the models however, showed that a considerable variation in the slopes of autonomous functioning (e.g., $\mathrm{u}_{1 j}$ for study efforts $=0.06, p<0.01$ ) with the $95 \%$ confidence interval (see Raudenbush \& Bryk, 2002) being ( -0.39 to 0.57 ) for study efforts, $(-0.40$ to 0.38$)$ for procrastination, $(-0.40$ to 0.90$)$ for subjective vitality and ( -0.95 to 0.47$)$ for depressive feelings. These ranges of scores suggest that in some particular weeks autonomous functioning did not relate to the dependent variables or even related to them in the opposite pattern than that shown in the model with the fixed effects.

Yet, in support of Hypothesis 2, the relation of autonomous functioning to the two study-related correlates, but not to the two affective ones, were moderated by entity beliefs (but also by gender). In particular, entity beliefs were found to moderate the week-to-week relations of autonomous functioning to study efforts $\left(\gamma_{10}=-0.06, S E=0.03, p<0.05\right)$ and homework procrastination $\left(\gamma_{11}=0.06, S E=0.03, p<0.05\right)$, but neither to subjective vitality $\left(\gamma_{10}=0.00, S E=0.04, p>0.05\right)$, nor to depressive feelings $\left(\gamma_{10}=0.01, S E=0.04, p>0.05\right)$. These findings suggest that a cognitive-based and academic-related personal characteristic (i.e., entity beliefs) qualified the relation of autonomous functioning to academic-related correlates, but not the relation of autonomous functioning to affect-related correlates such as subjective vitality and depressive feelings.

In regard to study efforts, a probe of the interactions (Bauer \& Curran, 2005; Preacher, Curran, \& Bauer, 2006) showed, in support of Hypothesis 2, that the association between autonomous functioning and study efforts was positive among students who held low (i.e., $1 S D$ below the mean) entity beliefs $\left(\gamma_{11}[-1 S D\right.$ entity beliefs $]=$ $0.17, S E=0.05, z=3.65, p<0.01)$ or average entity beliefs $\left(\gamma_{11 \text { [average entity beliefs] }}=0.09, S E=0.04, z=2.34, p<0.05\right)$; in contrast, it was non-significant among students who held high (i.e., $1 S D$ above the mean) entity beliefs $\left(\gamma_{11}[+1 S D\right.$ entity beliefs $]=0.01, S E=0.06$, $z=0.10, p=0.92$ ). This interaction is shown in Fig. 1. Regarding homework procrastination, a probe of the interactions revealed,

Table 1

Descriptive statistics and bivariate correlations of the measured variables of the study.

\begin{tabular}{|c|c|c|c|c|c|c|c|c|c|c|c|}
\hline Variables & 1 & 2 & 3 & 4 & 5 & 6 & 7 & 8 & 9 & $M$ & $S D$ \\
\hline 1. Gender & - & & & & & & & & & - & - \\
\hline 2. Perceived competence & -0.04 & - & & & & & & & & 3.75 & 0.76 \\
\hline 3. Entity beliefs & 0.01 & -0.08 & - & & & & & & & 3.74 & 1.31 \\
\hline 4. Mean autonomous functioning & 0.13 & $0.21^{* *}$ & -0.01 & - & & & & & & 3.80 & 0.87 \\
\hline 5. Mean study efforts & $0.16^{*}$ & $0.36^{* *}$ & $-0.31^{* *}$ & $0.23^{* *}$ & - & & & & & 2.89 & 0.70 \\
\hline 6. Mean homework procrastination & -0.13 & $-0.26^{* *}$ & $0.22^{* *}$ & $-0.26^{* *}$ & $-0.74^{* *}$ & - & & & & 3.11 & 0.70 \\
\hline 7. Mean subjective vitality & -0.07 & $0.18^{*}$ & -0.03 & $0.41^{* * *}$ & $0.31^{* *}$ & $-0.17^{*}$ & - & & & 3.32 & 0.75 \\
\hline 8. Mean depressive feelings & 0.05 & $-0.29^{* *}$ & 0.13 & $-0.50^{* *}$ & $-0.41^{* * *}$ & $0.47^{* *}$ & $-0.68^{* *}$ & - & & 2.61 & 0.63 \\
\hline 9. Grades & $0.15^{*}$ & $0.37^{* *}$ & $-0.21^{* *}$ & 0.10 & $0.41^{* * *}$ & $-0.27^{* *}$ & -0.02 & $-0.16^{*}$ & - & 15.32 & 2.84 \\
\hline
\end{tabular}

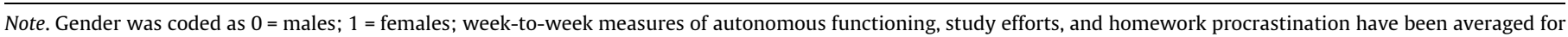
each individual.

${ }^{*} p<0.05$.

** $p<0.01$. 
Table 2

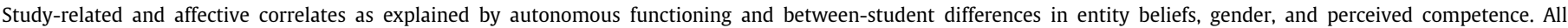
coefficients are in raw scores (standard errors in parentheses).

\begin{tabular}{|c|c|c|c|c|c|c|c|c|}
\hline \multirow{3}{*}{$\begin{array}{l}\text { Fixed effects } \\
\text { Intercept }\end{array}$} & \multicolumn{4}{|c|}{ Study-related correlates } & \multicolumn{4}{|c|}{ Affective correlates } \\
\hline & \multicolumn{2}{|c|}{ Study efforts } & \multicolumn{2}{|c|}{ Procrastination } & \multicolumn{2}{|l|}{ Vitality } & \multicolumn{2}{|c|}{ Depressive feelings } \\
\hline & 2.88 & $(0.05)$ & 3.12 & $(0.05)$ & 3.34 & $(0.06)$ & 2.58 & $(0.05)$ \\
\hline $\begin{array}{l}\text { Intrapersonal predictor } \\
\text { Autonomous functioning (AF) }\end{array}$ & $0.09^{*}$ & $(0.04)$ & -0.01 & $(0.04)$ & $0.25^{* *}$ & $(0.04)$ & $-0.24^{* *}$ & $(0.05)$ \\
\hline $\begin{array}{l}\text { Interpersonal predictor } \\
\text { Gender } \\
\text { Entity beliefs } \\
\text { Perceived competence }\end{array}$ & $\begin{array}{l}0.21^{*} \\
-0.13^{* *} \\
0.33^{* *}\end{array}$ & $\begin{array}{l}(0.10) \\
(0.03) \\
(0.06)\end{array}$ & $\begin{array}{l}0.18 \\
0.10^{*} \\
-0.24^{* *}\end{array}$ & $\begin{array}{l}(0.10) \\
(0.04) \\
(0.07)\end{array}$ & $\begin{array}{l}-0.09 \\
-0.01 \\
0.15^{*}\end{array}$ & $\begin{array}{l}(0.11) \\
(0.04) \\
(0.07)\end{array}$ & $\begin{array}{l}0.06 \\
0.05 \\
-0.22^{* *}\end{array}$ & $\begin{array}{l}(0.09) \\
(0.03) \\
(0.06)\end{array}$ \\
\hline $\begin{array}{l}\text { Cross-level interactions } \\
\text { AF X Gender } \\
\text { AF X Entity beliefs } \\
\text { AF X Perceived competence } \\
\text { Random effects } \\
\text { Intercept } \\
\text { Autonomous functioning slopes, } u_{1 j} \\
\text { Level } 1 \text { residuals }\end{array}$ & $\begin{array}{l}0.18^{*} \\
-0.06^{*} \\
-0.08 \\
\text { Variance } \\
0.33^{* *} \\
0.06^{* *} \\
0.25\end{array}$ & $\begin{array}{c}(0.08) \\
(0.03) \\
(0.04) \\
\text { nents }\end{array}$ & $\begin{array}{l}-0.16^{*} \\
0.06^{*} \\
0.05 \\
0.39^{* *} \\
0.04^{* *} \\
0.27\end{array}$ & $\begin{array}{l}(0.07) \\
(0.03) \\
(0.05)\end{array}$ & $\begin{array}{l}0.28^{*} \\
0.00 \\
0.07 \\
\\
0.45^{* *} \\
0.11^{* *} \\
0.35\end{array}$ & $\begin{array}{l}(0.09) \\
(0.04) \\
(0.07)\end{array}$ & $\begin{array}{l}-0.13 \\
0.01 \\
-0.04 \\
\\
0.30^{* *} \\
0.13^{* *} \\
0.23\end{array}$ & $\begin{array}{l}(0.09) \\
(0.04) \\
(0.07)\end{array}$ \\
\hline $\begin{array}{l}\text { Null model variance lying at the } \\
\text { Intrapersonal level } \\
\text { Interpersonal level }\end{array}$ & $\begin{array}{l}39.98 \% \\
60.02 \%\end{array}$ & & $\begin{array}{l}39.63 \% \\
60.37 \%\end{array}$ & & $\begin{array}{l}48.17 \% \\
51.83 \%\end{array}$ & & $\begin{array}{l}48.04 \% \\
51.96 \%\end{array}$ & \\
\hline $\begin{array}{l}\text { \% Variance explained at the } \\
\text { Intrapersonal level } \\
\text { Interpersonal level }\end{array}$ & $\begin{array}{l}10.53 \% \\
24.12 \%\end{array}$ & & $\begin{array}{l}6.88 \% \\
11.79 \%\end{array}$ & & $\begin{array}{l}15.20 \% \\
1.07 \%\end{array}$ & & $\begin{array}{l}20.56 \% \\
8.63 \%\end{array}$ & \\
\hline
\end{tabular}

Gender is dummy coded $(-0.5=$ males, $0.5=$ females $)$.

${ }^{*} p<0.05$.

** $p<0.01$.

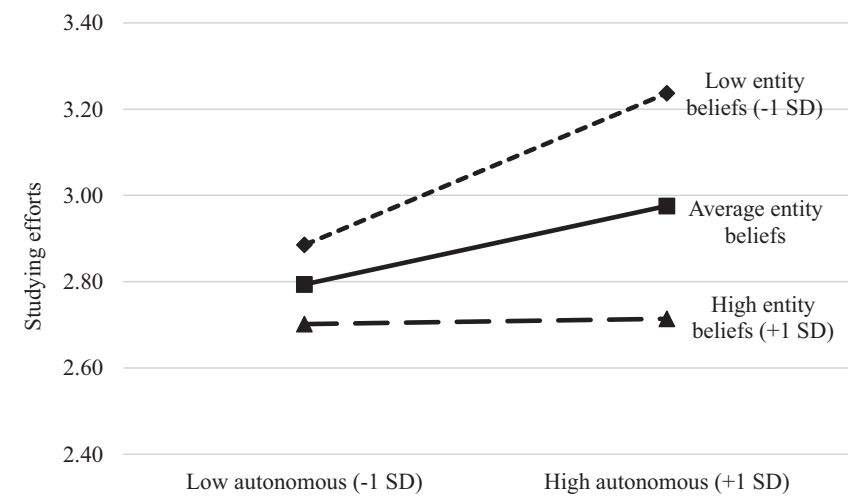

Fig. 1. The cross-level interaction between entity beliefs and autonomous functioning on the prediction of study efforts.

in partial support of Hypothesis 2, that its relation to autonomous functioning was negative, albeit marginally significant, only among students who held low entity beliefs $\left(\gamma_{11}[-1 S D\right.$ entity beliefs] $=-0.09$, $S E=0.05, z=-1.88, p=0.06$ ). Instead, this relation was statistically nonsignificant among students who held average or high levels of entity beliefs $\left(\gamma_{11}\right.$ [average entity beliefs] $=-0.01, S E=0.04, z=-0.27$, $p=0.78$ and $\gamma_{11}[+1 S D$ entity beliefs] $=0.07, S E=0.06, z=1.25, p=0.21$, respectively). These interactions, shown in Fig. 2 , are elaborated in the discussion section.

Concerning the cross-level interactions that were found between gender and autonomous functioning with respect to study efforts, procrastination, and vitality (see Table 2), a probe of interactions showed that the relation between autonomous functioning and study efforts was positive and statistically significant only among females $\left(\gamma_{10}\right.$ [females] $=0.18, S E=0.05, z=3.56$, $p=0.01$ ), whereas it was nonsignificant among males $\left(\gamma_{10}\right.$ [males] $\left.=0.00, S E=0.06, z=-0.02, p=0.98\right)$. The relation between autonomous functioning and homework procrastination was negative, yet marginally significant, among females

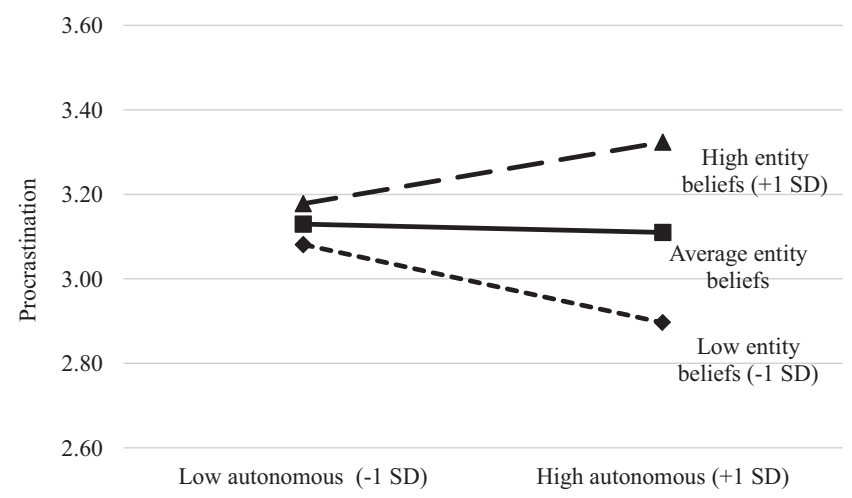

Fig. 2. The cross-level interaction between entity beliefs and autonomous functioning on the prediction of procrastination.

(i.e., $\gamma_{10 \text { [females] }}=-0.08, S E=0.05, z=-1.91, p=0.06$ ); instead, it was nonsignificant among males $\gamma_{10}$ [males] $=0.07, S E=0.06$, $z=1.27, p=0.20)$. Regarding subjective vitality, its positive relation to autonomous functioning was marginally significant among males $\left(\gamma_{10}\right.$ [males] $\left.=0.11, S E=0.06, z=1.86, p=0.06\right)$, whereas it was much stronger among females $\left(\gamma_{10}\right.$ [males] $=0.39, S E=0.07$, $z=5.87, p<0.01$; see Fig. 3). In sum, these results suggest that females tended to take more advantage than males the days they were autonomously functioning as they were more likely to regulate their study efforts better, to procrastinate less, and to feel more energized than males.

At the between-student level (see Table 2) and with respect to the study-related correlates, entity beliefs predicted negatively (between-student differences in) study efforts $\left(\gamma_{01}=-0.13\right)$ and positively (between-student differences in) procrastination $\left(\gamma_{01}=0.10\right)$ while it did not predict the two affective correlates, either. This finding provided support to Hypothesis 3. Unlike entity beliefs however, perceived competence was a significant predictor of both the study-related and the affective correlates. Specifically, 


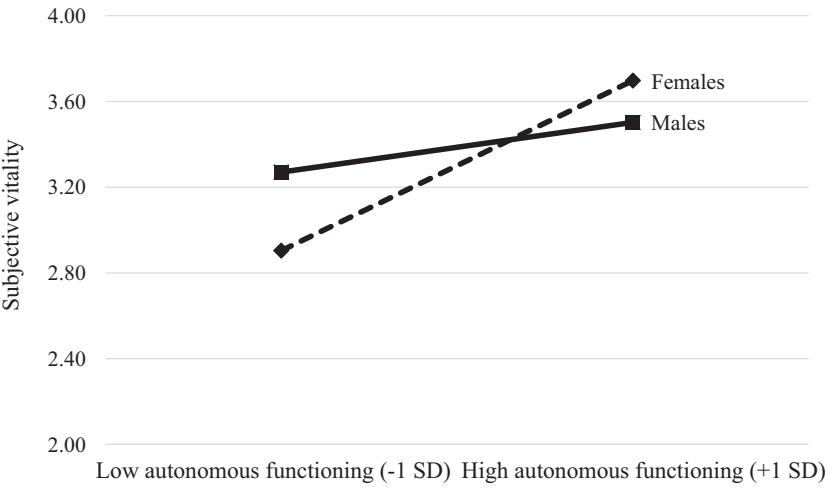

Fig. 3. The cross-level interaction between gender and autonomous functioning on the prediction of subjective vitality. (Points to be plot for males: 3.2705 \& 3.5023; for females: $2.904 \& 3.6974$.)

students who reported higher levels of school-related perceived competence reported, on average, more study efforts $\left(\gamma_{02}=0.31\right)$ and subjective vitality $\left(\gamma_{02}=0.15\right)$ and less procrastination $\left(\gamma_{02}=-0.23\right)$ and depressive feelings $\left(\gamma_{02}=-0.22\right)$.

\subsubsection{Supplementary analyses}

In supplementary analyses we tested, whether the intrapersonal relation between autonomous functioning and the studied correlates differ as a function of the stability of autonomous functioning. These tests showed that the relation of week-to-week autonomous functioning to study efforts, vitality, and depression was weaker among students who showed high fluctuation of week-to-week autonomous functioning. Finally, to check whether the between-person relations replicate prior studies, we tested, after controlling for gender and perceived competence, whether entity beliefs would predict grades and whether aggregated scores of study efforts and homework procrastination would mediate this association. Regression analyses showed that entity beliefs, as assessed at the mid of the school year, predicted lower grades six months later $(B=-0.41, S E=0.15, \beta=-0.19, p<0.01)$, whereas path analyses (see Fig. 4 ) showed that entity beliefs were indirectly associated with grades through aggregated scores of study efforts ( $\beta=-0.08, z=-2.67, p<0.01$ ). This finding suggests that study efforts act as a mechanism that perhaps explains the links between beliefs that ability is a fixed characteristic and school performance.

\section{Discussion}

In this research we focused on the dynamics of motivational processes and found week-to-week autonomous functioning that relates to subjective vitality positively and to depressive feelings negatively. Interestingly, although autonomous functioning related, as expected, in a consistent way to affective correlates, it was somewhat differentially related to study efforts and homework procrastination on a week-to-week basis, depending on students' entity beliefs. Furthermore, we found that entity beliefs predicted higher mean levels of homework procrastination and lower mean levels of study efforts, with the latter mediating also the negative link between entity beliefs and grades. All these associations were revealed after controlling for perceived competence. Our discussion is organized about the core issues of this research, namely, (a) the need to endorse a more micro-analytical approach to examine school-related motivational processes and outcomes; (b) the importance of autonomous functioning, as this is reflected through self-awareness, and the necessity to study the interplay between domain-specific determinants (e.g., beliefs about the nature of the academic-related ability) and situation-specific predictors (e.g., week-to-week autonomous functioning) of students' study-related behavior and affect-related experiences; and (c) the key role of implicit theories on students' regulation and behavior.

\subsection{On the dynamics of motivation}

Using the everyday experience methods protocol, we tried to separate intrapersonal processes from between-person differences and therefore to examine the persistence of links between students' motivation and aspects of study regulation (study efforts and procrastination) and well-being (subjective vitality and depressive feelings). Moreover, we tested whether these links are altered by students' implicit theories of ability (Reis \& Gable, 2000). Instead of asking students to retrospect over an extensive period of time about their autonomous functioning, study regulation, and well-being (a method which is more likely to induce bias - see Bolger, Davis, \& Rafaeli, 2003), we considered and found that students' school-related functioning is subjected to considerable variability from week to week. Perhaps this finding should come as no surprise when research has indicated that even personality characteristics, which are presumed to remain relatively stable

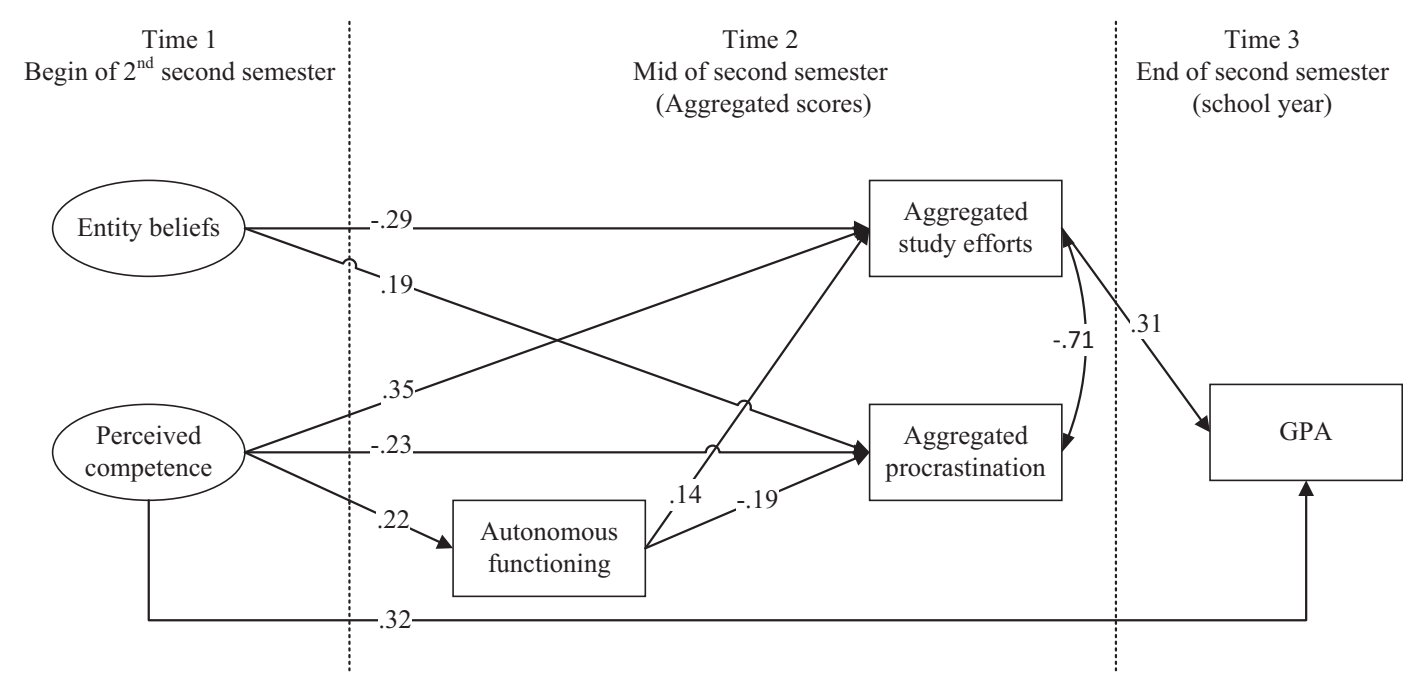

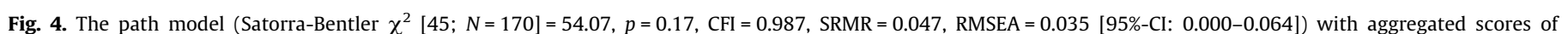

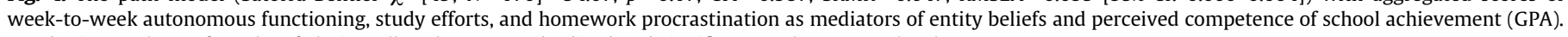
Gender is not shown for sake of clarity. All paths are standardized and significant at the $p=0.05$ level. 
across time, are subject to variation during shorter periods of time (Tennen, Affleck, \& Armeli, 2005). What is noteworthy, however, is the dearth of such studies in the educational context.

We argue that we need more studies focusing on the week-toweek (or day-to-day) associations between motivational processes and correlates. Consider for instance controlled motivation. Using a diary-method approach we may better understand to what extent controlled motivation relates in a consistent way to certain negative correlates or whether such links are moderated by students' certain personal characteristics (e.g., general need satisfaction or perfectionism) or contextual features (e.g., classroom environment). Such moderation effects were found in our study as the week-to-week relations of autonomous functioning to study efforts and procrastination differed among students depending on their implicit theories of ability (and gender). Apart from the personal characteristics as potential moderators of the intrapersonal relations between motivational processes and correlates, we need more studies that will investigate how the context of the classroom may moderate - either independently or in conjunction with personal characteristics - such intrapersonal relations. For instance, will an expected positive relation between week-toweek autonomous functioning and learning correlates become even stronger in classrooms with better motivational (e.g., needsupportive) environment? Given the premises of SDT (Deci \& Ryan, 2000) and the sensitization hypothesis (Moller et al., 2010) we are tempted to argue that this will be the case, but no evidence has been provided yet for such a speculation.

\subsection{Autonomous functioning at school}

The week-to-week relations between autonomous functioning and correlates revealed two noteworthy findings. First, the relations were subject to considerable week-to-week variation, with autonomous functioning being unrelated (or even related in an opposite-than-what-expected direction) to the correlates Second, some of these rather "inconsistent" associations could be explained when students' ability beliefs were considered. As our analyses indicated, autonomous functioning indeed related positively to study efforts and negatively (albeit marginally) to homework procrastination among students who believed, at least to some degree, that ability can be developed.

Should we focused on the between-person differences (as we did in supplementary analyses), we would have found that autonomous functioning relates positively to study efforts and negatively to homework procrastination. Would these analyses be sufficient to understand the patterns of associations among these variables? No, because we obtained a different picture when we focused on the intrapersonal variation and on top of them we considered students' ability beliefs. Most likely, several other variables lying at the between-person level, such as domain-specific autonomous motivation (e.g., Moller et al., 2010) or gender (for which we did find also to moderate the week-to-week relations of autonomous functioning to the three out of the four studied correlates), or at the contextual level such as the motivational environment of the classroom may provide an insight into the motivational dynamics. The fact that supplementary analyses further showed that the intrapersonal relation between autonomous functioning and some of the correlates differed because of fluctuation of autonomous functioning further underscores the necessity to search for potential moderators that may alter the dynamics of intrapersonal motivational processes.

Regarding the absence of relation between autonomous functioning and the study correlates among students who held high entity beliefs, we cannot but discuss it in light of similar findings that have been reported from prior diary studies. At first glance, this lack of associations appears to challenge somehow the basic principles of SDT (Deci \& Ryan, 2000) according to which people benefit when they function in an autonomous way. We cannot but agree with this premise. Besides, numerous studies have provided adequate support for the link between autonomous functioning and well adjustment. But what exactly all these reports show? They show that, on average, autonomous functioning relates positively to desired correlates. Does this relation mean that all people who are autonomously functioning always experience, for instance more positive affect or persist more in an adverse situation? As our research implies it seems that not all people may benefit, at least to the same degree, because some of them may benefit less during "shining days". Partial support for this claim is provided by Reis et al. (2000) who in their diary study have shown daily autonomous functioning to be unrelated to well-being among people who were low in trait-like self-determined motivation (see also Moller et al., 2010; Sheldon et al., 1996).

Apparently, there are numerous factors which once we take into account they can enable us predict in a more precise way under what circumstances a person with certain personal characteristics will be more likely to benefit, when he or she is autonomously functioning. Our proposition aims to draw researchers' attention to a likely "Simpson's paradox". According to Simpson paradox, an association that is observed in different sub-groups (say, a negative week-toweek relation between variables A and B at the intrapersonal level) may be reversed when the data are pooled (i.e., the negative intrapersonal relation between variables $A$ and $B$ may become positive when the data are aggregated at the student level) (Kievit, Frankenhuis, Waldorp, \& Borsboom, 2013). Using “Simpson's paradox" as a springboard, we are wondering whether the direction of an association at the interpersonal-level (when people are asked to provide summary accounts of their psychological states and experiences - see Bolger et al., 2003) may sometimes be reversed (or be absent) at the intrapersonal level (when we assess the same constructs in a more dynamic, day-to-day way). Certainly, more research is needed to investigate this issue and we hope that our research might contribute towards that direction.

\subsection{Implicit theories}

As our study has pointed out, the students who believed that ability is a fixed trait, had lower grades in the end of the school year and put less study efforts halfway the school year, even after controlling for perceived academic-related competence. This finding underscores the debilitating role of entity beliefs because it implies that high-perceived competence may not cancel out the negative relation of entity beliefs to grades. A student, who believes that she has the skills to attain her academic-related goals, may not protect her against performance decrements as long as she believes that ability can hardly be developed. Considering also that entity beliefs were unrelated to perceived competence, this finding suggests that students construe their beliefs that ability is fixed or malleable irrespective of their competence perceptions (Dweck \& Leggett, 1988).

The negative relation between entity beliefs and grades fits well with past reports, which have shown similar negative associations between entity beliefs and school-related performance (Blackwell et al., 2007) and efforts or effort attributions (Hong et al., 1999; Rattan, Good, \& Dweck, 2012). Although our research was correlational, it complements the few experimental studies (e.g., Hong et al., 1999) and the even fewer qualitative ones (Heyman \& Dweck, 1998) that have linked entity beliefs to decreased efforts. It does so because it shows in an ecologically valid setting, and through a longitudinal research design, that (self-reported) study regulation - and not only beliefs about the nature of effort (see Blackwell et al., 2007) or effort attributions (Hong et al., 1999) relate to decreased study efforts and increased homework 
procrastination. In fact, these results fully align with a recent diary study which has shown that entity beliefs predicted lower mean levels of study efforts and higher mean levels of procrastination (Rickert, Meras, \& Witkow, 2014). Apparently, a student who believes that his or her ability is fixed is more susceptible to question the usefulness of effort and hard work to attain a goal.

Our research has further revealed that students who held entity beliefs not only tended to report decreased study efforts but also to benefit less the days that they felt that they were autonomously functioning. Are these days passed underexploited among people with a fixed mindset? Obviously, more research is needed to have a concrete answer on this question but extrapolating from the few diary studies which have shown that daily need satisfaction is less strongly related with daily well-being among people who fail to satisfy their basic psychological needs in general (Moller et al., 2010; Sheldon et al., 1996), we are tempted to suggest that people with strong entity beliefs may not see a reason to study hard, or not to procrastinate, even during the "shining days".

\subsection{Gender differences}

Although not a central issue, our study showed some gender differences in study efforts with females reporting studying harder from week to week than males. Although we found no similar differences in procrastination or the well-being indices, there is some evidence in the literature showing that females are more meticulous in doing their homework than males (Glasgow, Dornbusch, Troyer, Steinberg, \& Ritter, 1997; Trautwein, Luedtke, Kastens, \& Koeller, 2006). What seems more interesting however is that gender moderated the week-to-week associations between autonomous functioning and study efforts as well as procrastination and subjective vitality. These moderating effects suggest that females were more likely to take advantage of their autonomous functioning. Are female adolescent students more sensitive, in accordance with the sensitization hypothesis (Moller et al., 2010), than their male counterparts? Partial support for this claim is coming from Flook (2011) who showed in a diary study with adolescents that the relation between daily events and mood was stronger among females than males and from prior research which has shown that females experience more intense emotions than males (Fujita, Diener, \& Sandvik, 1991). These reports perhaps explain why in the present study females, as compared to males, reported for instance more vitality the days they felt being autonomous. As no firm conclusion can be drawn yet, we cannot but invite future replication studies to confirm or refute our speculation for such differences.

\subsection{Practical implications}

Our results can be translated into education practice in certain ways. First, the fact that entity beliefs were found to predict lower grades, study efforts, and homework procrastination and to moderate the links between week-to-week autonomous functioning and study efforts or homework procrastination, it becomes clear that students' fixed mindset should be altered in the first place. Having adolescents believing that ability cannot be developed relates to a host of negative motivational processes and correlates. Fortunately, prior research has shown that altering such mindset is feasible (Blackwell et al., 2007; Yeager et al., 2013).

We suggest that genuinely praising effort, attributing success in mastery or learning to hard work, highlighting occasions where a student has improved, linking present striving for learning with potential future outcomes, and providing examples from famous scientists whose deeds were the product of their hard work represent a few examples of hints that teachers could integrate in their everyday teaching practice. In few words, teachers (and parents) need to foster a learning environment that emphasizes striving for mastery, learning, and improvement through effort (Ames, 1992). Such a learning environment should be autonomoussupportive as well, given the positive relation between autonomous functioning and aspects of study regulation and well-being. This could be accomplished if teachers, and parents, (a) nurture adolescents' inner motivational resources by rendering class tasks interesting, enjoying, and challenging; (b) take adolescents perspective and (c) be empathetic towards them (Reeve \& Jang, 2006; Reeve, Jang, Carrell, Jeon, \& Barch, 2004).

\subsection{Limitations}

Our study contains several limitations that should be mentioned. First, despite its short-term longitudinal design, the study is correlational in nature. Therefore, we cannot infer causality between autonomous functioning and study efforts or procrastination or between entity beliefs and subsequent self-reported motivational processes and outcomes as such an approach would require an experimental research design. Second, only with caution can we generalize the present results to students of other ages or educational systems. Obviously, future replication studies are needed to test the generalizability of the present findings. Also, future studies need to examine whether the week-to-week patterns of associations between autonomous functioning and correlates remain invariant across time (e.g., during the first versus last weeks of a school year) age (e.g., among early versus late adolescents), and - more important - contexts (e.g., among students belonging to need supportive versus need suppressing classrooms). Third, we focused only on two certain study-related (i.e., study efforts and procrastination) and affect-related (i.e., subjective vitality and depressive feelings) correlates; hence for the time being we cannot tell whether the same patterns will emerge if we consider other motivational processes (e.g., competence need satisfaction) and correlates (e.g., positive affect). Finally, with the exception of grades, our analyses were based on self-reports and therefore are susceptible to a monomethod bias. We suggest that future diary studies need to include multiple informants to test the patterns of associations among entity beliefs, autonomous functioning, and motivational correlates.

\subsection{Conclusion}

Our short-term diary study focused on the ongoing dynamics of students' motivation and provides some evidence for a week-toweek fluctuation of students' autonomous functioning and aspects of study regulation (i.e., study efforts and homework procrastination) and well-being (i.e., subjective vitality and depressive feelings). When looking at the intrapersonal fluctuation, it seems that the more students feel autonomous functioning, the more effort they put in studying and the less they procrastinate; also, the more they feel energetic and the less depressive symptoms they admit. However, a closer inspection shows that this pattern seems particularly true among female students. Also, with respect to the study-related correlates this pattern seems to apply mainly among those who believe that school-related ability can be developed. When looking at the between-person differences, a certain maladaptive pattern was found among students with entity beliefs as such students were less likely to persist in studying and therefore they were less likely to get higher grades.

\section{References}

Ames, C. (1992). Classrooms: Goals, structures, and student motivation. Journal of Educational Psychology, 84, 261-271. http://dx.doi.org/10.1037/00220663.84.3.261. 
Bartholomew, K. J., Ntoumanis, N., Ryan, R. M., Bosch, J. A., \& Thogersen-Ntoumani, C. (2011). Self-determination theory and diminished functioning: The role of interpersonal control and psychological need thwarting. Personality and Social Psychology Bulletin, 37, 1459-1473. http://dx.doi.org/10.1177/ 0146167211413125.

Bauer, D. J., \& Curran, P. J. (2005). Probing interactions in fixed and multilevel regression: Inferential and graphical techniques. Multivariate Behavioral Research, 40, 373-400. http://dx.doi.org/10.1207/s15327906mbr4003 5 .

Blackwell, L. S., Trzesniewski, K. H., \& Dweck, C. S. (2007). Implicit theories of intelligence predict achievement across an adolescent transition: A longitudinal study and an intervention. Child Development, 78, 246-263. http://dx.doi.org/ 10.1111/j.1467-8624.2007.00995.x.

Bodill, K., \& Roberts, L. D. (2013). Implicit theories of intelligence and academic locus of control as predictors of studying behaviour. Learning and Individua Differences, 27, 163-166. http://dx.doi.org/10.1016/j.lindif.2013.08.001.

Bolger, N., Davis, A., \& Rafaeli, E. (2003). Diary methods: Capturing life as it is lived. Annual Review of Psychology, 54, 579-616. http://dx.doi.org/10.1146/annurev. psych.54.101601.145030.

Braasch, J. L. G., Braten, I., Stromso, H. I., \& Anmarkrud, O. (2014). Incremental theories of intelligence predict multiple document comprehension. Learning and Individual Differences, 31, 11-20. http://dx.doi.org/10.1016/j. lindif.2013.12.012.

Burnette, J. L., O’Boyle, E. H., VanEpps, E. M., Pollack, J. M., \& Finkel, E. J. (2013). Mindsets matter: A meta-analytic review of implicit theories and self-regulation. Psychological Bulletin, 139, 655-701. http://dx.doi.org/10.1037/a0029531.

Cain, K. M. \& Dweck, C. S. (1995). The relation between motivational patterns and achievement cognitions through the elementary-school years. Merrill-Palme Quarterly-Journal of Developmental Psychology, 41, 25-52.

Cronbach, L. J., \& Meehl, P. E. (1955). Construct validity in psychological tests. Psychological Bulletin, 52, 281.

Cury, F., Da Fonseca, D., Zahn, I., \& Elliot, A. (2008). Implicit theories and IQ test performance: A sequential mediational analysis. Journal of Experimental Social Psychology, 44, 783-791. http://dx.doi.org/10.1016/j.jesp.2007.07.003.

Cury, F., Elliot, A. J., Da Fonseca, D., \& Moller, A. C. (2006). The social-cognitive model of achievement motivation and the $2 \times 2$ achievement goal framework. Journa of Personality and Social Psychology, 90, 666-679. http://dx.doi.org/10.1037 0022-3514.90.4.666.

Deci, E. L., Eghrari, H., Patrick, B. C., \& Leone, D. R. (1994). Facilitating internalization - The self-determination theory perspective. Journal of Personality, 62, 119-142. http://dx.doi.org/10.1111/j.1467-6494.1994.tb00797.x.

Deci, E. L., \& Ryan, R. M. (2000). The "what" and "why" of goal pursuits: Human needs and the self-determination of behavior. Psychological Inquiry, 11 227-268. http://dx.doi.org/10.1207/s15327965pli1104_01.

Depreeuw, E. (1998). Vragenlijst aangaande Studie-Organisatie-Vaardigheden-Va-SOV [Study management skills: A questionnaire]. Unpublished manuscript. Leuven, Belgium: Center for Research in Motivation and Time Perspective, Catholic University.

Dweck, C. S. (1986). Motivational processes affecting learning. American Psychologist, 41, 1040-1048. http://dx.doi.org/10.1037//0003-066x.41.10.1040.

Dweck, C. S. (1999). Self-theories: Their role in motivation, personality, and development. Philadelphia: Psychology Press.

Dweck, C. S., Chiu, C.-Y., \& Hong, Y.-Y. (1995). Implicit theories: Elaboration and extension of the model. Psychological Inquiry, 6, 322-333. http://dx.doi.org 10.1207/s15327965pli0604_12.

Dweck, C. S., \& Leggett, E. L. (1988). A social cognitive approach to motivation and personality. Psychological Review, 95, 256-273. http://dx.doi.org/10.1037/| 0033-295x.95.2.256.

Enders, C. K., \& Tofighi, D. (2007). Centering predictor variables in cross-sectional multilevel models: A new look at an old issue. Psychological Methods, 12 121-138. http://dx.doi.org/10.1037/1082-989x.12.2.121.

Flook, L. (2011). Gender differences in adolescents' daily interpersonal events and well-being. Child Development, 82, 454-461. http://dx.doi.org/10.1111/j.14678624.2010.01521.x

Fujita, F., Diener, E., \& Sandvik, E. (1991). Gender differences in negative affect and well-being: The case for emotional intensity. Journal of Personality and Social Psychology, 61, 427-434. http://dx.doi.org/10.1037/0022-3514.61.3.427.

Gagné, M., Ryan, R. M., \& Bargmann, K. (2003). Autonomy support and need satisfaction in the motivation and well-being of gymnasts. Journal of Applied Sport Psychology, 15, 372-390. http://dx.doi.org/10.1080/10413200390238031.

Geldhof, G. J., Preacher, K. J., \& Zyphur, M. J. (2014). Reliability estimation in multilevel confirmatory factor analysis framework. Psychological Methods, 19, 72-91. http://dx.doi.org/10.1037/a0032138.

Glasgow, K. L., Dornbusch, S. M., Troyer, L., Steinberg, L., \& Ritter, P. L. (1997) Parenting styles, adolescents' attributions, and educational outcomes in nine heterogeneous high schools. Child Development, 68, 507-529. http://dx.doi.org/ $10.2307 / 1131675$

Grolnick, W. S., Ryan, R. M., \& Deci, E. L. (1991). Inner resources for schoolachievement: Motivational mediators of children's perceptions of their parents. Journal of Educational Psychology, 83, 508-517. http://dx.doi.org/10.1037/00220663.83.4.508

Guay, F., Ratelle, C. F., \& Chanal, J. (2008). Optimal learning in optimal contexts: The role of self-determination in education. Canadian Psychology-Psychologie Canadienne, 49, 233-240. http://dx.doi.org/10.1037/a0012758.

Haimovitz, K., Wormington, S. V., \& Corpus, J. H. (2011). Dangerous mindsets: How beliefs about intelligence predict motivational change. Learning and Individual Differences, 21, 747-752. http://dx.doi.org/10.1016/j.lindif.2011.09.002.
Heyman, G. D., \& Dweck, C. S. (1998). Children's thinking about traits: Implications for judgements of the self and others. Child Development, 69, 391-403. http://dx. doi.org/10.1111/j.1467-8624.1998.tb06197.x.

Hong, Y. Y., Chiu, C. Y., Dweck, C. S., Lin, D. M. S., \& Wan, W. (1999). Implicit theories, attributions, and coping: A meaning system approach. Journal of Personality and Social Psychology, 77, 588-599. http://dx.doi.org/10.1037//0022-3514.77.3.588.

Howell, A. J., \& Buro, K. (2009). Implicit beliefs, achievement goals, and procrastination: A mediational analysis. Learning and Individual Differences, 19, 151-154. http://dx.doi.org/10.1016/j.lindif.2008.08.006.

Jones, B. D., Wilkins, J. L. M., Long, M. H., \& Wang, F. H. (2012). Testing a motivational model of achievement: How students' mathematical beliefs and interests are related to their achievement. European Journal of Psychology of Education, 27. 1-20. http://dx.doi.org/10.1007/s10212-011-0062-9.

Katz, I., Eilot, K., \& Nevo, N. (2014). "I'll do it later": Type of motivation, self-efficacy and homework procrastination. Motivation and Emotion, 38, 111-119. http://dx. doi.org/10.1007/s11031-013-9366-1.

Kievit, R. A., Frankenhuis, W. E., Waldorp, L. J., \& Borsboom, D. (2013). Simpson's paradox in psychological science: a practical guide. Frontiers in Psychology, 4. http://dx.doi.org/10.3389/fpsyg.2013.00513.

King, R. B., McInerney, D. M., \& Watkins, D. A. (2012). How you think about your intelligence determines how you feel in school: The role of theories of intelligence on academic emotions. Learning and Individual Differences, 22, 814-819. http://dx.doi.org/10.1016/j.lindif.2012.04.005.

Lay, C. H. (1986). At last, my research article on procrastination. Journal of Research in Personality, 20, 474-495. http://dx.doi.org/10.1016/0092-6566(86) 90127-3.

Martin, A. J., Nejad, H. G., Colmar, S., \& Liem, G. A. D. (2013). Adaptability: How students' responses to uncertainty and novelty predict their academic and nonacademic outcomes. Journal of Educational Psychology, 105, 728-746. http://dx. doi.org/10.1037/a0032794.

McAuley, E., Duncan, T., \& Tammen, V. V. (1989). Psychometric properties of the intrinsic motivation inventory in a competitive sport setting: A confirmatory factor analysis. Research Quarterly for Exercise and Sport, 60, 48-58.

Molden, D. C., \& Dweck, C. S. (2006). Finding "meaning" in psychology - A lay theories approach to self-regulation, social perception, and social development. American Psychologist, 61, 192-203. http://dx.doi.org/10.1037/0003066x.61.3.192.

Moller, A. C., Deci, E. L., \& Elliot, A. J. (2010). Person-level relatedness and the incremental value of relating. Personality and Social Psychology Bulletin, 36, 754-767. http://dx.doi.org/10.1177/0146167210371622.

Oberle, E., Schonert-Reichl, K. A., Lawlor, M. S., \& Thomson, K. C. (2012). Mindfulness and inhibitory control in early adolescence. The Journal of Early Adolescence, 32, 565-588. http://dx.doi.org/10.1177/0272431611403741.

Patrick, H., Knee, C. R., Canevello, A., \& Lonsbary, C. (2007). The role of need fulfillment in relationship functioning and well-being: A self-determination theory perspective. Journal of Personality and Social Psychology, 92, 434-457. http://dx.doi.org/10.1037/0022-3514.92.3.434.

Pintrich, P. R., Smith, D., Garcia, T., \& McKeachie, W. J. (1991). A manual for the use of the motivated strategies for learning questionnaire (MSLQ). Ann Arbor, MI: National Center for Research to Improve Postsecondary Teaching and Learning, University of Michigan.

Preacher, K. J., Curran, P. J., \& Bauer, D. J. (2006). Computational tools for probbing interactions in multiple regression, multilevel modeling, and latent curve analysis. Journal of Educational and Behavioral Statistics, 31, 437-448.

Radloff, L. S. (1977). The CES-D scale: A self-report depression scale for research in the general population. Applied Psychological Measurement, 1, 385-401. http:// dx.doi.org/10.1177/014662167700100306.

Rattan, A., Good, C., \& Dweck, C. S. (2012). "It's ok - Not everyone can be good at math": Instructors with an entity theory comfort (and demotivate) students. Journal of Experimental Social Psychology, 48, 731-737. http://dx.doi.org/ 10.1016/j.jesp.2011.12.012.

Raudenbush, S. W., \& Bryk, A. S. (2002). Hierarchical linear models: Applications and data analysis methods (2nd ed.). Thousand Oaks: CA: Sage.

Reeve, J., \& Jang, H. (2006). What teachers say and do to support students' autonomy during a learning activity. Journal of Educational Psychology, 98, 209-218. http:// dx.doi.org/10.1037/0022-0663.98.1.209.

Reeve, J., Jang, H., Carrell, D., Jeon, S., \& Barch, J. (2004). Enhancing students' engagement by increasing teachers' autonomy support. Motivation and Emotion, 28, 147-169. http://dx.doi.org/10.1023/B:Moem. 0000032312.95499.6f.

Reis, H. T., \& Gable, S. L. (2000). Event-sampling and other methods for studying everyday experience. In H. T. Reis \& C. M. Judd (Eds.), Handbook of research methods in social and personality psychology (pp. 190-222). New York: Cambridge University Press.

Reis, H. T., Sheldon, K. M., Gable, S. L., Roscoe, J., \& Ryan, R. M. (2000). Daily wellbeing: The role of autonomy, competence, and relatedness. Personality and Social Psychology Bulletin, 26, 419-435. http://dx.doi.org/10.1177/ 0146167200266002

Rickert, N. P., Meras, I. L., \& Witkow, M. R. (2014). Theories of intelligence and students' daily self-handicapping behaviors, Learning and Individual Differences, 36, 1-8. http://dx.doi.org/10.1016/j.lindif.2014.08.002.

Romero, C., Master, A., Paunesku, D., Dweck, C. S., \& Gross, J. J. (2014). Academic and emotional functioning in middle school: The role of implicit theories. Emotion, 14, 227-234. http://dx.doi.org/10.1037/a0035490.

Ryan, R. M., \& Frederick, C. (1997). On energy, personality, and health: Subjective vitality as a dynamic reflection of well-being. Journal of Personality, 65, 529-565. http://dx.doi.org/10.1111/j.1467-6494.1997.tb00326.x. 
66

A. Mouratidis et al./Contemporary Educational Psychology 48 (2017) 56-66

Ryan, R. M., Huta, V., \& Deci, E. L. (2008). Living well: A self-determination theory perspective on eudaimonia. Journal of Happiness Studies, 9, 139-170. http://dx. doi.org/10.1007/s10902-006-9023-4.

Ryan, R. M., Miss, V., \& Koestner, R. (1983). Relation of reward contingency and interpersonal context to intrinsic motivation - A review and test using cognitive evaluation theory. Journal of Personality and Social Psychology, 45, 736-750. http://dx.doi.org/10.1037//0022-3514.45.4.736.

Senecal, C., Julien, E., \& Guay, F. (2003). Role conflict and academic procrastination: A self-determination perspective. European Journal of Social Psychology, 33, 135-145. http://dx.doi.org/10.1002/ejsp.144.

Sheldon, K., \& Decl, E. L. (1996). The Self-determination scale. Unpublished manuscript. University of Rochester.

Sheldon, K. M., \& Niemiec, C. P. (2006). It's not just the amount that counts: Balanced need satisfaction also affects well-being. Journal of Personality and Social Psychology, 91, 331-341. http://dx.doi.org/10.1037/0022-3514.91.2.331.

Sheldon, K., Ryan, R., \& Reis, H. T. (1996). What makes for a good day? Competence and autonomy in the day and in the person. Personality and Social Psychology Bulletin, 22, 1270-1279. http://dx.doi.org/10.1177/01461672962212007.

Shell, D. F., \& Human, J. (2008). Control, motivation, affect, and strategic selfregulation in the college classroom: A multidimensional phenomenon. Journal of Educational Psychology, 100, 443-459. http://dx.doi.org/10.1037/00220663.100.2.443.

Tennen, H., Affleck, G., \& Armeli, S. (2005). Personality and daily experience revisited. Journal of Personality, 73, 1465-1483. http://dx.doi.org/10.1111/ j.1467-6494.2005.00355.x.

Trautwein, U., Luedtke, O., Kastens, C., \& Koeller, O. (2006). Effort on homework in grades 5-9: Development, motivational antecedents, and the association with effort on classwork. Child Development, 77, 1094-1111. http://dx.doi.org/ 10.1111/j.1467-8624.2006.00921.x.
Vallerand, R. J., Fortier, M. S., \& Guay, F. (1997). Self-determination and persistence in a real-life setting: Toward a motivational model of high school dropout. Journal of Personality and Social Psychology, 72, 1161-1176. http://dx.doi.org/ 10.1037/0022-3514.72.5.1161.

Vansteenkiste, M., Zhou, M., Lens, W., \& Soenens, B. (2005). Experiences of autonomy and control among Chinese learners: Vitalizing or immobilizing? Journal of Educational Psychology, 97, 468-483. http://dx.doi.org/10.1037/00220663.97.3.468.

Weinstein, N., Przybylski, A. K., \& Ryan, R. M. (2013). The integrative process: New research and future directions. Current Directions in Psychological Science, 22, 69-74. http://dx.doi.org/10.1177/0963721412468001.

Winfield, A., \& Eccles, J. S. (2000). Expectancy-value theory of achievement motivation. Contemporary Educational Psychology, 25, 68-81. http://dx.doi.org/ 10.1006/ceps.1999.1015.

Yeager, D. S., \& Dweck, C. S. (2012). Mindsets that promote resilience: When students believe that personal characteristics can be developed. Educational Psychologist, 47, 302-314. http://dx.doi.org/10.1080/00461520.2012.722805.

Yeager, D. S., Johnson, R., Spritzer, B. J., Trzesniewski, K. H., Powers, J., \& Dweck, C. S. (2014). The far-reaching effects of believing people can change: Implicit theories of personality shape stress, health, and achievement during adolescence. Journal of Personality and Social Psychology, 106, 867-884. http:// dx.doi.org/10.1037/a0036335.

Yeager, D. S., Trzesniewski, K. H., \& Dweck, C. S. (2013). An implicit theories of personality intervention reduces adolescent aggression in response to victimization and exclusion. Child Development, 84, 970-988. http://dx.doi. org/10.1111/cdev.12003. 